\title{
Scanning Transmission Electron Microscopy of SiAION/Graphene Nano Platelets Composites Obtained with a Novel Homogenization Approach
}

\author{
Umut SAVACI ${ }^{1}$, Alper CINAR ${ }^{1}$, A. Tugrul SEYHAN ${ }^{1}$ and Servet TURAN ${ }^{1}$ \\ 1. Anadolu University, Faculty of Engineering, Department of Materials Science and Engineering, \\ Eskisehir, TURKEY
}

SiAlON ceramics have gained attraction as an engineering material due to their superior mechanical properties, thermal stability, creep resistance and corrosion resistance [1]. Thanks to its properties these ceramics are used for engineering applications like cutting tools, ball bearings and etc, where not only the mechanical properties but also thermal conductivity has significant importance in order to remove produced heat from work zone [2]. Graphene is the most promising candidate to improve thermal conductivity due to its extraordinary thermal properties to overcome heat transfer problem from work zone [3]. Graphene addition can also improve the electrical conductivity of naturally electrical insulator SiAlON ceramics and this can allow electro-discharge machining for shaping and manufacturing.

The aim of this study is to characterize the graphene platelets containing SiAlON ceramic matrix composites by using transmission electron microscopy techniques. For this purpose composite samples were prepared by using spark plasma sintering of SiAlON forming powders $\left(\mathrm{Si}_{3} \mathrm{~N}_{4}, \mathrm{AlN}, \mathrm{Al}_{2} \mathrm{O}_{3}, \mathrm{CaCO}_{3}\right.$, $\mathrm{Y}_{2} \mathrm{O}_{3}$, and $\mathrm{Sm}_{2} \mathrm{O}_{3}$ ) and $4 \mathrm{wt} \%$ graphene flakes exfoliated by microfluidization process with commercial microfluidizer (Microfluidics M-110P) with 30,000 psi constant pump pressure for 16 cycles. Powder mixture was homogenized with ball mill prior to spark plasma sintering at $1950^{\circ} \mathrm{C}$ under $50 \mathrm{MPa}$ for 10 minutes. Transmission electron microscopy sample was prepared by conventional mechanical polishing method followed by Ar-ion beam thinning (Leica Microsystems EM-RES101). Electron transparent samples were examined by using 200kV field emission TEM (JEOL-JEM2100F) in STEM mode with HAADF detector (Model 3000, Fischione) and energy dispersive spectroscopy (EDX JEOL-JED2300T).

XRD results, which are not given in here, showed that only $\beta$-SiAlON and graphene phases exist after sintering.

In the Z-contrast HAADF-STEM images (Figure 1) three different intensity levels are observed. Bright intensity regions at grain boundaries and grain junctions belong to high atomic number rare earth sintering additive phases with Y, Ca and Sm. Features at lowest intensity level are exfoliated graphene flakes due to the fact that it is the lowest atomic number element in the composite and SiAlON grains appear with an intermediate intensity level. According to the results, it can be clearly seen that graphite platelets are in various sizes and located at grain junctions. STEM-HAADF images also support SEM results, which are not given in here; graphene platelets between the grains limit the grain growth. STEM analyses also showed that liquid phase that is formed during sintering can enter between graphene platelets located at grain junctions.

The STEM-EDX analyses support HAADF images, line scan analysis (Figure 1d) show the variation of Si $\left(\mathrm{Si}-\mathrm{K}_{\alpha}\right)$ and $\mathrm{C}\left(\mathrm{C}-\mathrm{K}_{\alpha}\right)$ elements along the line. Supplementary to the line scans, EDX elemental maps (Figure 2) show the distribution of characteristic $\mathrm{C}-\mathrm{K}_{\alpha}(0.28 \mathrm{keV}), \mathrm{N}-\mathrm{K}_{\alpha}(0.39 \mathrm{keV}), \mathrm{Al}-\mathrm{K}_{\alpha}(1.49 \mathrm{keV})$, Si-K $\mathrm{K}_{\alpha}(1.74 \mathrm{keV})$, and $\mathrm{Y}-\mathrm{L}_{\alpha}(1.92 \mathrm{keV}) \mathrm{X}$-ray lines. 


\section{References:}

[1] K.M. Fox, J.R. Hellman, Int. J. Appl. Ceram. Technol. 5 (2008) p138-154.

[2] P. Rutkowski, L. Stobierski, G. Gorny, J. Therm. Anal. Calorim. 116 (2014) p321-328.

[3] J.H. Warner et al " Graphene: fundamentals and emergent applications", (Elsevier, Oxford), 2013

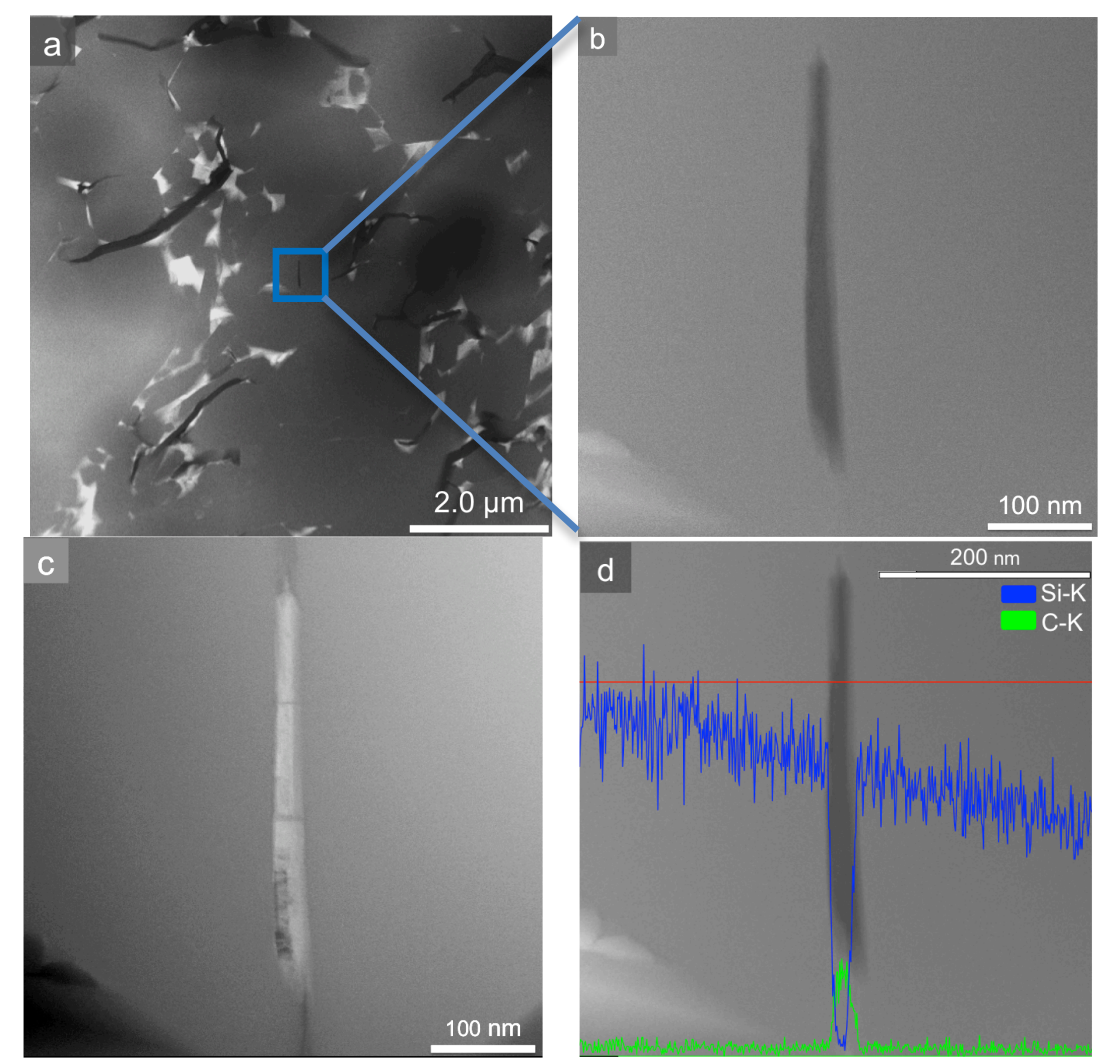

Figure 1. (a-b) STEM-HAADF, (c) STEM-BF and (d) EDX line scan analysis of graphene/SiAlON composite.
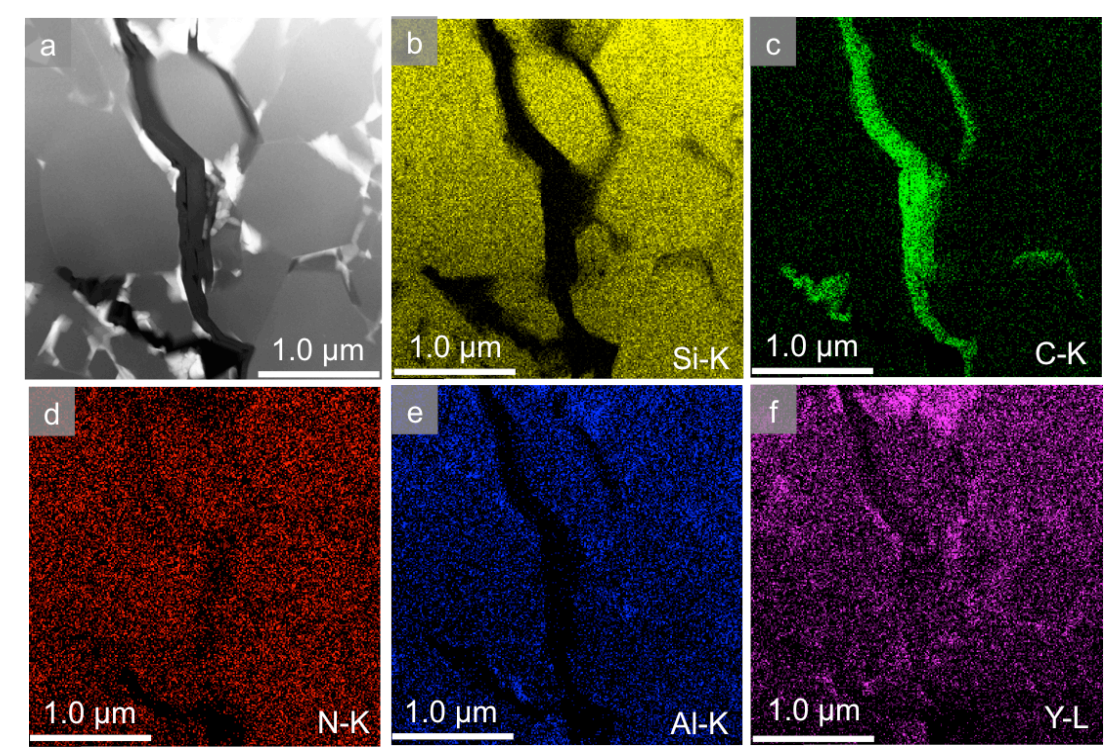

Figure 2. (a) STEM-HAADF image and (b-f) X-ray elemental maps of graphene/SiAlON composite. 